\title{
FARMERS' VIEWS AND ATTITUDES TOWARDS THE REFORMED COMMON AGRICULTURAL POLICY IN GREECE
}

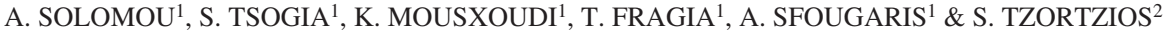 \\ ${ }^{1}$ Laboratory of Ecosystem and Biodiversity Management, Department of Agriculture, Crop Production and Rural \\ Environment, University of Thessaly, Volos, Greece. \\ ${ }^{2}$ Laboratory of Biometry, Department of Agriculture, Crop Production and Rural Environment, University of Thessaly, \\ Volos, Greece.
}

\section{ABSTRACT}

The agricultural industry constitutes a productive sector that plays a vital role in the financial, social and ecological balance of any agricultural area. Therefore, the support for an intended complete development of agriculture is - and it will always be - a primary duty of all governments worldwide. In the present study, the results of a research, which was conducted in five Greek Prefectures (Chania, Korinthia, Trikala, Grevena and Evros) during the period 2005-2007, focused on the assessment of farmers' views towards the new Common Agricultural Policy (CAP) are presented. In particular, the aims of the research focused on the ways by which farmers may be informed and the level of their knowledge with regard to the CAP, farmers' views and attitudes towards the new measures suggested by the CAP, the advantages and disadvantages of the present productive system and finally, the contemporary trends of agriculture and some farmers' attributes. The research was conducted by use of questionnaires which were filled out by each farmer during an interview. In total, 1,200 farmers were interviewed (300 in every prefecture, except Trikala and Grevena where the sample included 150 farmers each). The questionnaire consisted of 41 specific questions in total. The data processing was carried out by using the SPSS statistical package. The research led to the conclusion that farmers' awareness with regard to the CAP, its revision, the procedures which are foreseen by it and the benefits which can result from its provisions for farmers' income was restricted. Therefore, it is obvious that there is a need for applying more effective methods with regard to the circulation of relevant information. For these methods, some proposals have been presented. An attempt is undertaken to present certain proposals aiming at further improvement.

Keywords: Common Agricultural Policy, farmers'views, Greece, reforms.

\section{INTRODUCTION}

The agricultural industry constitutes a productive sector that plays a vital role in the financial, social and ecological balance of any agricultural area. Therefore, the support for an intended complete development of agriculture is - and it will always be - a primary obligation of the state in every country. Referring particularly to Greece, the fulfilment of this obligation is an intervention of utmost 'social interest' [1].

Recent surveys show that in EU the number of people employed in agriculture is 14 million, without including the provisional workers, a number that corresponds to $5.2 \%$ of the total EU workers. The number of people who consume agricultural products is 490 million in the EU, while the average expenditure of households for feeding, drinks and tobacco is $16.9 \%$ out of their total expenditure. The total area used for farming purposes is estimated to be 182 million hectares; the income generated in the agricultural section is about $€ 325$ billion. It is worth pointing out that the export of agricultural products corresponds to $6.5 \%$ of the total exports of the EU [2].

The total area of Greece is $13,194,400$ ha, $30 \%$ of which is cultivated land, $46 \%$ rangelands, $19 \%$ forests, $2 \%$ is covered by water (rivers, lakes and marshland) and $3 \%$ is urban areas. With regard to the cultivable land, $75.8 \%$ of it is arable, $3.15 \%$ gardens, $6.7 \%$ vineyards and $14.45 \%$ orchards and tobacco [3]. As for the climate of the country, it is of the Mediterranean type, with a high variability from region to region, allowing the cultivation of a great variety of crops. 
Since the 1950s, Agricultural Policy has been the basis of the European Policy. Historically, the incorporation of agricultural products in the main principles of the Common Market as well as the institution of special rules of competition for agriculture constituted a very important decision for the adoption of a Common Policy in the agricultural sector [4].

Since 1981, Greek agriculture is governed by the rules of the Common Agricultural Policy (CAP) and has evolved with regard to the corresponding changes of the CAP [5]. In its course, CAP has undergone many reforms, sometimes radical, and it has evolved in a manner that corresponds to the changing needs of the society. The reduction in the number of people employed in the agricultural sector has resulted in a reduction in the financing percentage from EU sources, which corresponds to the CAP [6]. The last reform of CAP took place in 2003-2004. On one hand, it was imposed by the need to limit the funds of communal budget for agriculture until 2013, in view of the expansion of the EU. On the other hand, this reform was imposed to adjust the reinforcements of agricultural sector according to the guidelines of the World Trade Organization (WTO) [7]. The last reform was completed in 2007.

The issues concerning the environment played a central role in the formation of the agricultural policy, both as a means of facing the environmental consequences and as a means of providing supplementary compensation to farmers [8]. The social interest focuses more on the disturbed balance of the ecosystem to such an extent that a great percentage of the public opinion in Greece regards the countryside not only as a source which provides food but also as an important source of environmental goods [9]. The CAP will continue to operate in a supportive way for farmers - and the rural area in general - until 2013. Afterwards, the immediate financial support to the agricultural and livestock-raising sectors will be eliminated (products, utilization, etc.). In other words, the new CAP introduces new principles for a sustainable agricultural sector [10]. The successive reforms of the CAP that have been made to date have not solved sufficiently the problems and difficulties faced by a big part of the Greek agricultural population. Therefore a more robust CAP should be enforced, which will monitor the needs and challenges and maintain the agricultural activity in all areas of the EU [11].

The implementation of the new CAP raises in Greek agriculture the challenge to adjust quickly with regard to structural problems, thus contributing to the formation of a satisfactory agricultural income. However, a determinant which can lead to higher viability of agricultural exploitations seems to be the general situation of the national economy during the next few years and the evolution of employment in the secondary and tertiary sector [12]. Through the implementation of the new CAP, Greece needs improvement in both farmers' income and life, while at the same time satisfying the demands for the protection of the environment and the sustainable management of natural resources. The multi-functional model of European agriculture should continue, allowing Greek as well as other European farmers to remain in the countryside and keep producing safe and high quality products [13].

\section{METHODOLOGY}

This research was conducted in five prefectures and based on a sample of 1,200 farmers [Chania (300), Korinthia (300), Evros (300), Trikala (150) and Grevena (150)] (Fig. 1) [14]. The method used was a gallup poll, which involved the use of questionnaires that were filled out during personal interviews with every farmer of the sample; the interviews were conducted during the period 2005-2007. The questionnaire (consisting of 41 questions) was given to each farmer by the researcher who had already explained the purpose of the research and the meaning of the questions. The interviewee was given time to fill out the questionnaire without being interrupted, thereby giving them the chance to ask for further clarification for some questions during its completion. The analysis of the answers in 


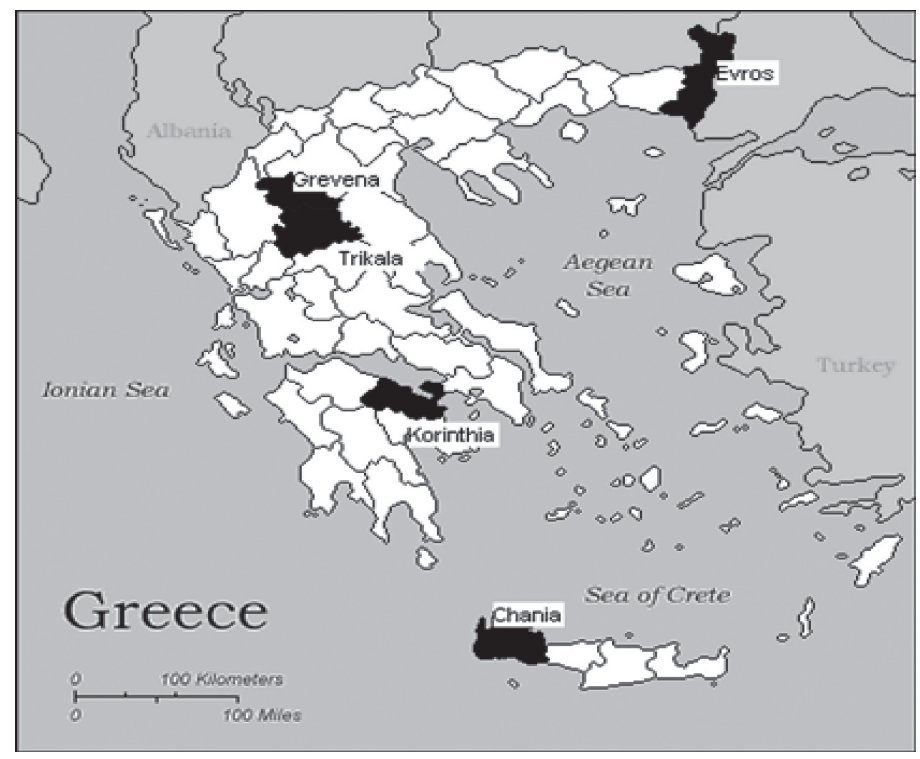

Figure 1: Study area.

the questionnaires was carried out by using the SPSS package, after coding the answers [15]. For the closed-type questions, that is, yes or no questions, the codes 1 or 0 were used, respectively, while for the multiple-choice questions the codes $\mathrm{A}$ or B or $\mathrm{C}$ or $\mathrm{D}$ and the codes 0 or 1 or 2 were used.

\section{RESULTS AND DISCUSSION}

The aging of the population employed in the agricultural sector and the difficulty in the succession of agricultural exploitation are the main structural problems of the European agriculture. The fact that senior citizens stay more in business and the high cost of setting up an agricultural business are important obstacles for the continuation of the exploitation. The profile of aging, which is presented by the constantly aging agricultural population of Europe, shows different trends and evolutions based on the Member State and the kind of the agriculture practiced [16].

With regard to the age of the participants (Fig. 2), the data from the research showed that $17.8 \%$ were $20-30$ years old, $36.7 \%$ were $30-40$ years old, $13.1 \%$ were $50-60$ years old, $25.7 \%$ were $40-50$ years old and $5.4 \%$ were $>60$ years old. In Greece, the ageing of the agricultural population, the abandonment of some crops, the depopulation of the countryside and the abandonment of whole villages are some factors negatively affecting the future agriculture. The future prospects show that this trend will not stop here. The agricultural population is decreasing, from $29.2 \%$ in 1981 to $17.85 \%$ in 1998 and $12.6 \%$ in 2004, while the aim of the present European policy is to reach 8\% [17]. The analysis of the data showed that for $69 \%$ of the participants agriculture was the main occupation, while $30.9 \%$ of them were farmers for a supplementary income (Fig. 3). Doing two jobs at the same time is due to the fact that farmers try to have alternatives with regard to their job so as to have a supplementary income. Moreover, the results showed that $65 \%$ of the arable land in Chania Prefecture and $30.3 \%$ in Korinthia Prefecture are covered by olive groves, while $46.2 \%$ of the arable land in Evros Prefecture and $41.3 \%$ in Grevena and Trikala Prefectures are covered by wheat.

As for farmers' satisfaction concerning their product prices, it was observed (Fig. 4) that 92.4\% were not satisfied, while only $7.5 \%$ of them were satisfied. In any case, the base price is a strong 


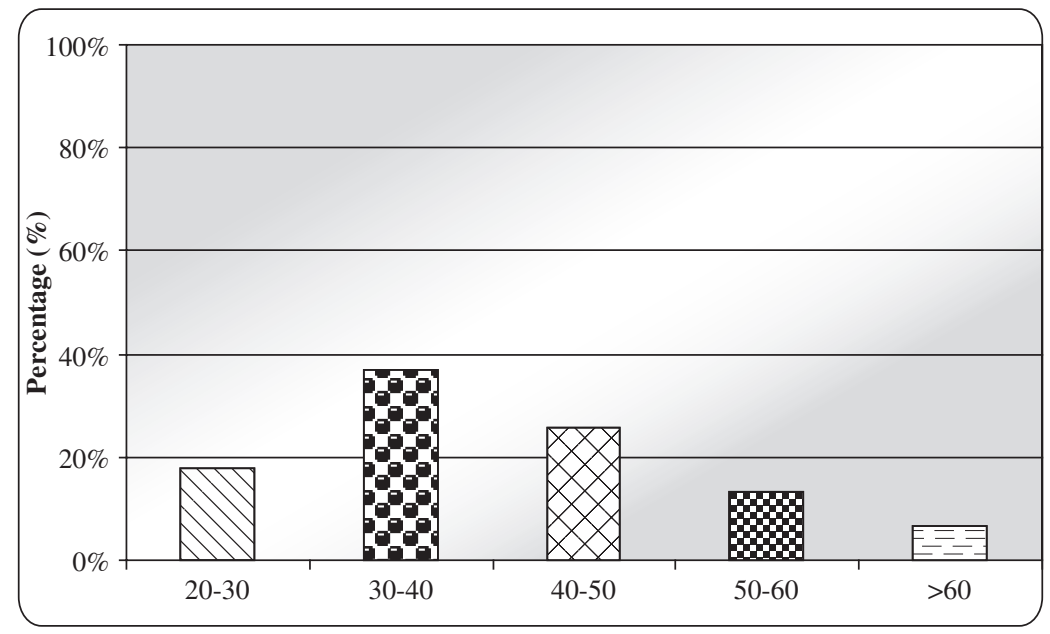

Figure 2: Farmers' age.

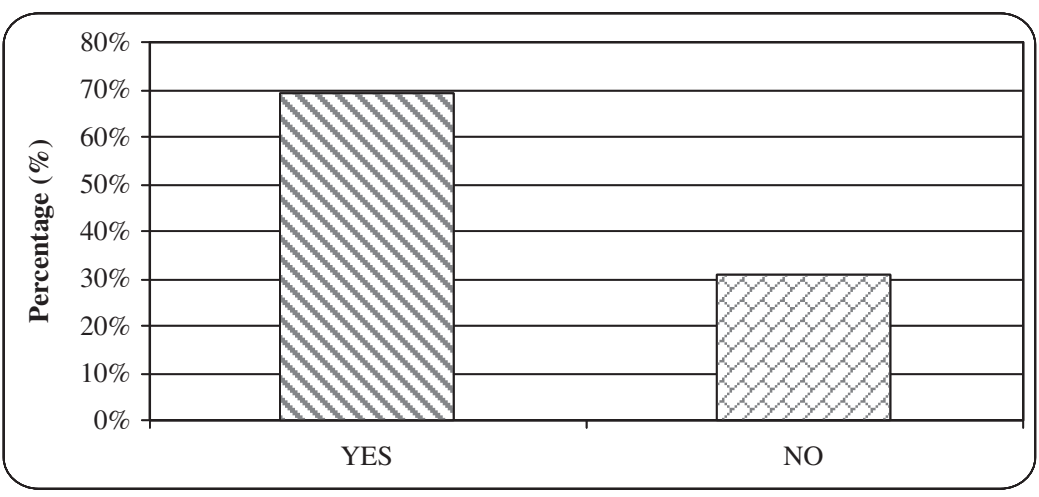

Figure 3: Percentage of the participants whose main job was agriculture.

basis and any change in it, not only in factual terms but also in nominal terms, should not be examined individually, if the consistency and the trust on the agricultural policy, which has to do with a multi-complex and important sector of the economy, are to be maintained [18]. As mentioned earlier, the agricultural population was dissatisfied with the prices of their products. The increase in competition at the international level decreased the prices constantly and consequently the agricultural income. This means that there has been a serious pressure in the less productive exploitations of our country which has forced farmers to abandon their crops and entire agricultural areas. Figure 5 shows that a high percentage of the participants $(45.8 \%$ ) replied that they would be satisfied with a price increase $>30 \%$ compared 


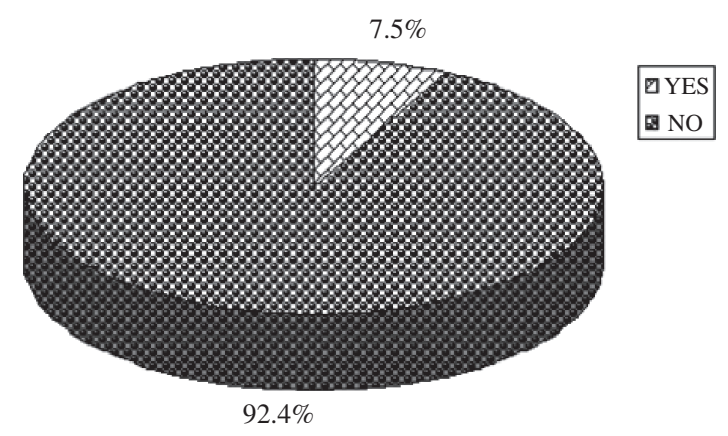

Figure 4: Farmers' satisfaction from the price of their products.

to the present prices. An increase of $30 \%$ in the price would satisfy $31.4 \%$ of the participants, while an increase of $20 \%$ would satisfy $15.78 \%$ of them. About $6.91 \%$ of the participants replied that they would be satisfied with an increase of $10 \%$ in price per unit of measurement of product. A majority of the farmers $(53.2 \%)$ replied that they could produce more, as they are not exclusively farmers and that the time they spend on other activities yields bigger profits than spending it on the maximization of their crop production, given the low prices and the increased cost of production. A high percentage $(60.2 \%)$ of the farmers (Fig. 6) considers that it is not necessary to change their crops. However, $39.7 \%$ of them believe that they should change them.

Of the answers given to the question 'why farmers should change crops', $35.1 \%$ responded 'because the product which they produce is not paid well in the market', $14.3 \%$ 'because their product is not absorbed by the market', $11.8 \%$ 'because their crop demands a lot of water', $12.8 \%$ 'because it demands a lot of fertilizers', $13.6 \%$ 'because their crop needs many pesticides' and $12.2 \%$ 'because it is not possible'. According to Fig. 7, 59\% of the participants did not know that the guaranteed prices, especially for some products, caused huge fiscal expenses in the EU.

Figure 8 shows that $74.1 \%$ of the participants did not know that the first reform of the CAP took place in 1992. Figure 9 shows that $61.5 \%$ of the participants were not informed about the other reforms in the CAP, only $11.9 \%$ knew about the other two reforms in 1999 and 2003 and 26.5\% knew nothing about the reforms that had been carried out and they gave wrong answers.

These data can be attributed to the low degree of education in the agricultural population and therefore seminars with instructional programs about agricultural issues should be organized so that farmers will always be informed. On the other hand, older farmers are not interested in being informed. In general, farmers' preparation and awareness for every change in the agricultural sector is usually restricted. The agricultural consultative services can be subsidized so as to offer professional help to the farmers to renovate their settlements, to adopt sustainable methods and to differentiate their activities [19]. In the question about the accession of new countries in the EU and its consequence on the Greek agricultural policy (Fig. 10), 65.2\% of the participants had a negative opinion, $13.1 \%$ had a positive opinion, while the remaining $21.5 \%$ had no opinion at all/did not know.

The WTO is a legally enacted organization of the world trade system. It defines the most important formal duties of its members which, in turn, define the way in which the governments plan and apply the legislation and the rules about internal market. It constitutes the basis on which the commercial bases of the countries are formed, through collective discussions, negotiations and decisions [20]. A majority of the agricultural population $(52.8 \%$ ) considers that the consequences of the present WTO policy in the agricultural sector are negative, contrary to $18.9 \%$ of the participants who are in favor 


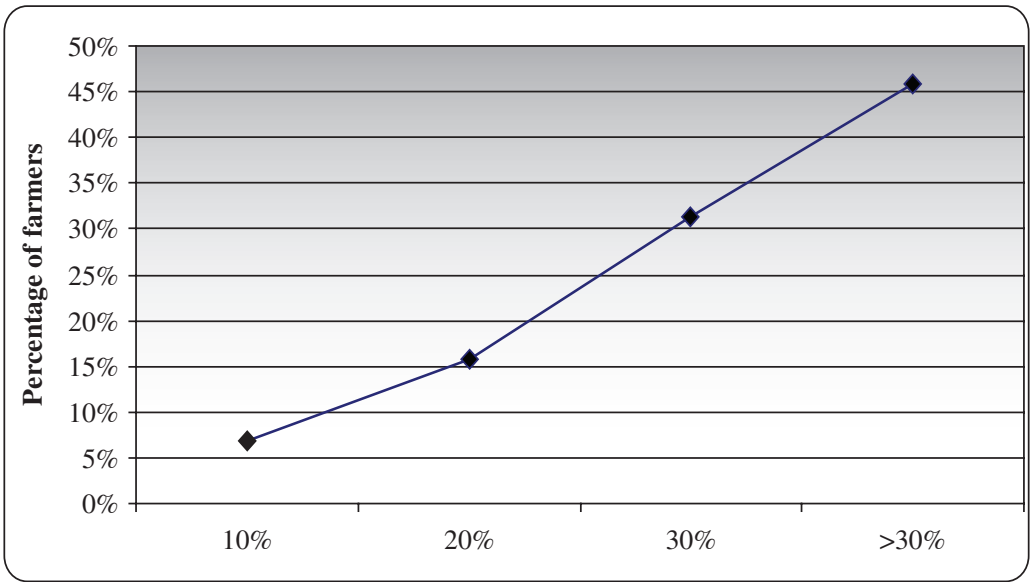

Figure 5: The desirable percentage of increase in the price of products.

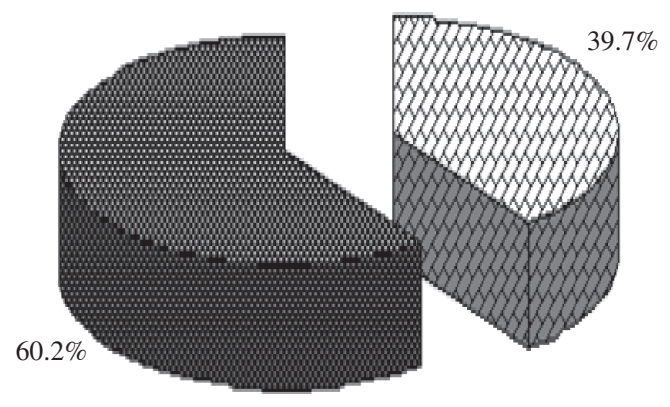

\section{Y YES \\ 图 NO}

Figure 6: Necessity for changing of crops.

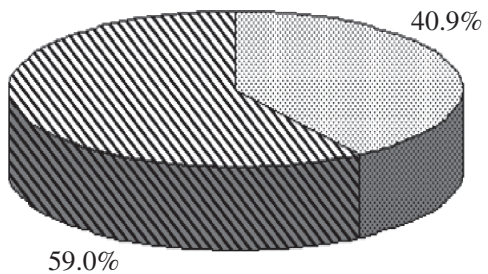

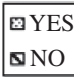

Figure 7: Farmers' knowledge about the fact that the guaranteed prices caused huge expenses in the EU. 


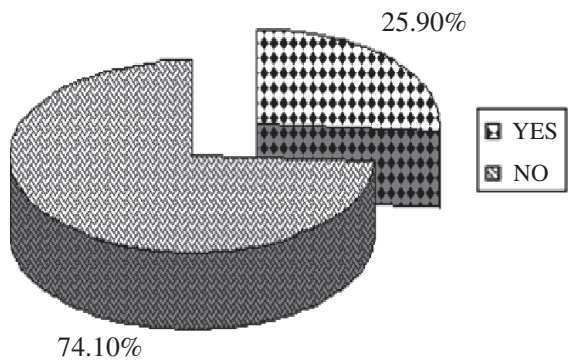

Figure 8: Awareness of farmers about the first reform of the CAP.

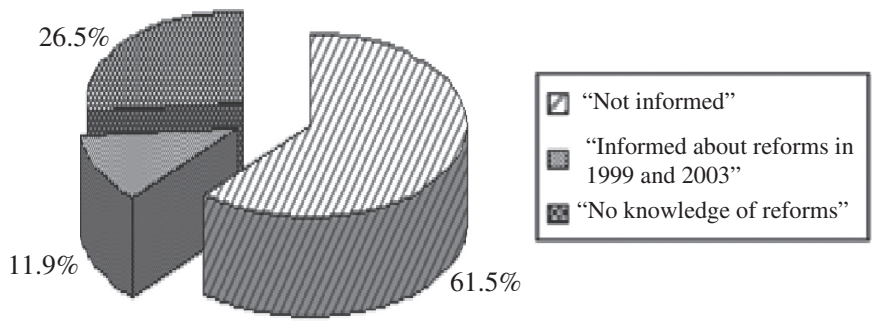

Figure 9: Farmers' awareness about the reforms of the CAP.

of its policy (Fig. 11). Again, the percentage of participants who knew nothing about it was high and so they did not express any opinion.

It should be understood that knowledge is the most important weapon to improve competition and reduce unemployment, which are the most important factors for the development and reconstruction of the agricultural sector [21]. Indeed, $71.5 \%$ of the participants believe that Greek farmers should be competitive in the globalized market by producing high quality products $(47.9 \%)$ with lower cost ( $40.8 \%$ ), because this is the only way for the farmers - and consequently for Greek agriculture - to stay in the market under the present conditions. The EU protects farmers by intervening when the prices of agricultural products drop below a certain level and buying the surplus of the communal supply until the prices rise above the intervention levels. The surplus is either destroyed or disposed at reduced prices in markets outside the EU, or it is sent out as aid for food to other countries [22]. However, $88.6 \%$ of the participants believe that the EU ought to continue its protective policy towards farmers and $76.2 \%$ believe that the Greek state should play an active role in the support of the agricultural income. The analysis of the answers showed that $54.1 \%$ of the sample takes a compensatory allowance and $33 \%$ of them agree with the maintenance of the 'Code of Good Agricultural Practice', while a high percentage $(58.1 \%$ ) knows nothing about it. About $38.1 \%$ of the sample receives financial support with co-responsibility and $35.6 \%$ goes through quotas of production. The farmers' awareness about European programs is deficient. They get information through informal sources: $43.4 \%$ replied that they are informed by friends, $20.7 \%$ by the agronomist in their area, $14.4 \%$ by the Department of Agricultural Development of the prefecture, $2.6 \%$ by groups of farmers and $18.7 \%$ in other ways (agricultural magazines, media, web, by chance) or they are never informed.

European programs support financially the investments that are accomplished in the agricultural sector so as to attract young farmers and to protect the environment. Moreover, the analysis of the 


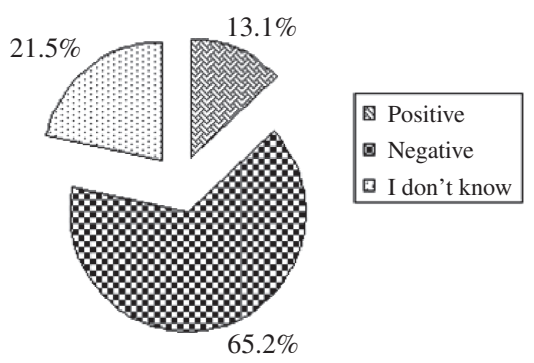

Figure 10: Farmer's attitudes towards the accession of new countries in the EU.

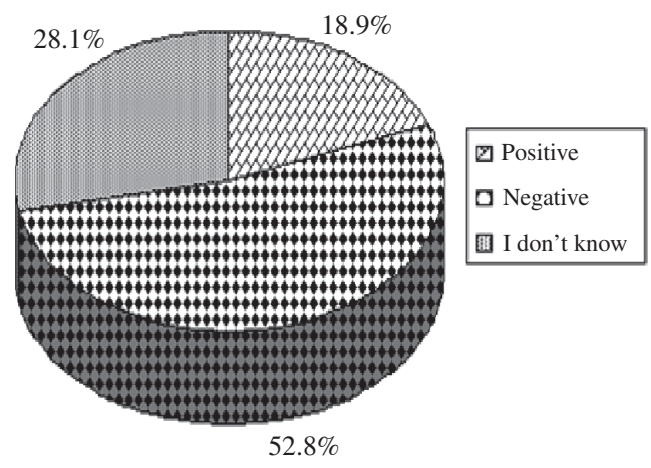

Figure 11: Farmers' attitudes towards the WTO.

questionnaires showed that for the question 'Are you entitled to a European Program?' (Fig. 12), 59.4\% replied that they had enrolled in the program 'New farmer', 24.4\% in the 'Biological agriculture' program, $5.1 \%$ in the 'Reduction of nitrogen pollution' program, $4.5 \%$ in the 'Long-term set aside' program, $3.7 \%$ in the LEADER program and $2.6 \%$ in other programs.

The system of cross compliance is one of the main components of the CAP reform in 2003. The system of cross compliance links the full payment, after following certain rules about the agricultural land and the agricultural production, with the activity in environmental sectors, public health and animal health as well as the good agricultural and environmental conditions. The system of cross compliance has two aims. Its first aim is to contribute to the development of a viable agriculture and the second aim is to help the CAP to respond better to the society's prospects [23]. At the same time, the Greek agricultural areas include protected areas, so if all the management measures are taken into account, with regard to the protection of the resources and the natural environment, it would be claimed that the protection of the environment is an important determinant for the evolution of the rural areas [24]. The analysis of the questionnaires showed that $78.1 \%$ agreed to cross compliance, according to which the full payment by the piece of communal backing will presuppose the observance of some criteria with regard to the environment, food safety, good animal conditions, etc. On the contrary, $9.2 \%$ did not agree with cross compliance, while $12.6 \%$ expressed ignorance. About $38.7 \%$ agree to the transmission of more money into structural programs instead of backing the price. 

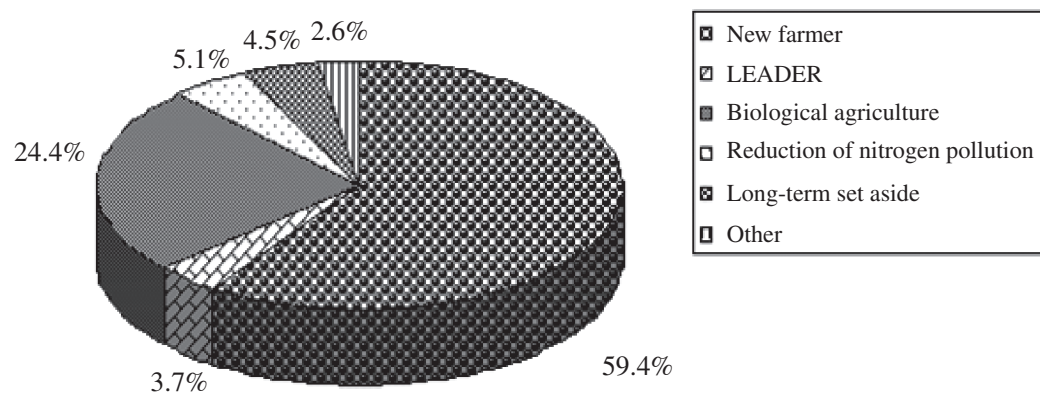

Figure 12: Participation in European programs.

Figure 13 shows the distribution of farmers' income. Compared with the data in 2000, the Greek farmers' income has decreased by $16.7 \%$ in contrast to the other countries of the EU where an important increase has been recorded or the income remained the same.

At present, the EU has realized that farmers need something more than a simple subsidy, and it has turned from the guarantee of price to a guarantee about the stability of the income through immediate payment, which is managed in each Member State by the Organization of Agricultural Payment. The new CAP, which was introduced in 2003, has brought about radical changes in the communities of the countryside. Farmers are the subject of a policy which is not only in the farmers' interest but also in society's interest [25]. The analysis of the questionnaires showed that $59.8 \%$ of the participants were not going to proceed with some action in order to protect their income from the pause in the guaranteed price, $15.3 \%$ replied that they have already made some alterations, $10 \%$ replied that they will utilize the programs of the EU and $14.7 \%$ replied that they will their change occupation.

In the second half of the 20th century, Greece turned from an entirely agricultural country to a country of tertiary sector. The highest decrease in the agricultural sector happened in the 1960s, the decade during which a large extent of the population left the agricultural areas and consequently agriculture itself [26]. The present research is an additional proof of the fear that the future of agriculture, not only in these five prefectures but all over Greece, is uncertain. Figure 14 shows that $76.7 \%$ of the participants who had children aged $>18$ years replied that none of their children would work in the agricultural sector and they justified their attitude by giving various reasons, among which the main one was 'the low agricultural income combined with the job being hard which forces their children to turn to more efficient jobs'.

With reference to the answers given to the question about the proposals as regards the agricultural policy, 36\% suggested that imports from third countries should be prohibited, $20 \%$ were in favor of financial support for agricultural and environmental measures, $12.5 \%$ suggested the investigation of the structural programs, $11.4 \%$ suggested an increase in intervention prices for all the agricultural products, $8.96 \%$ suggested an increase in the intervention prices for certain agricultural products, $5.1 \%$ suggested financial support without restrictions and criteria (as regards the quality, the environment, etc.), $2.7 \%$ suggested a decrease in the intervention prices of the agricultural products, $1.3 \%$ suggested a change of the environmental restrictions and $0.3 \%$ suggested an increase in exports.

\section{CONCLUSIONS}

The Greek farmers' awareness about CAP and its reforms is inadequate. There is ignorance about the Codes of Good Agricultural Practice and the main reasons for this are the lack of awareness and the low educational level. Farmers' attitude towards the accession of new countries in the EU and the WTO 


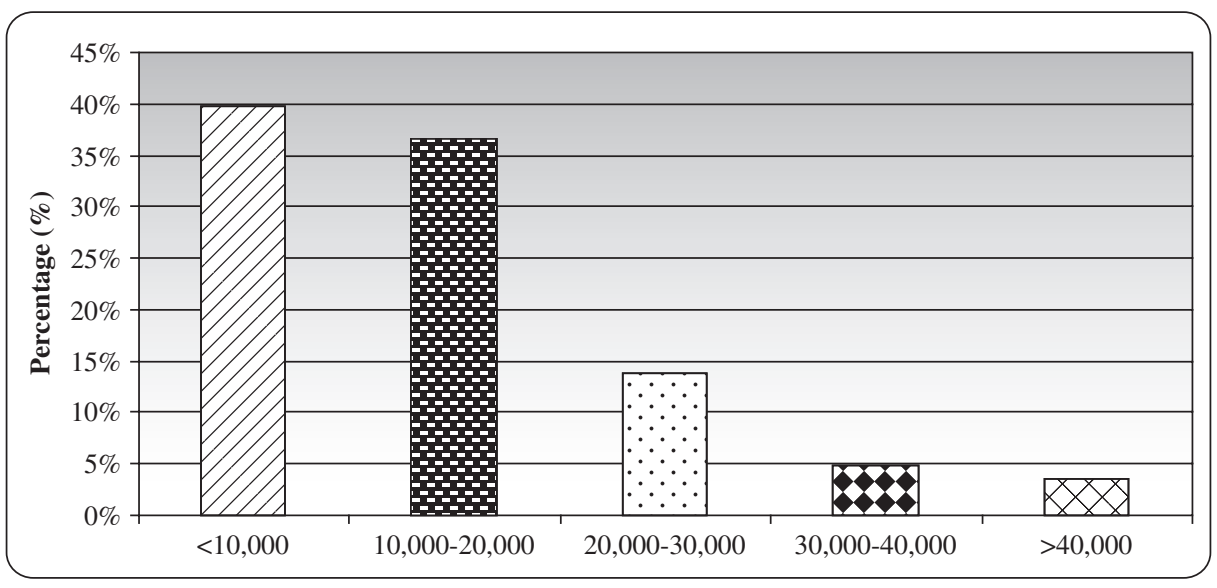

Figure 13: Annual income.

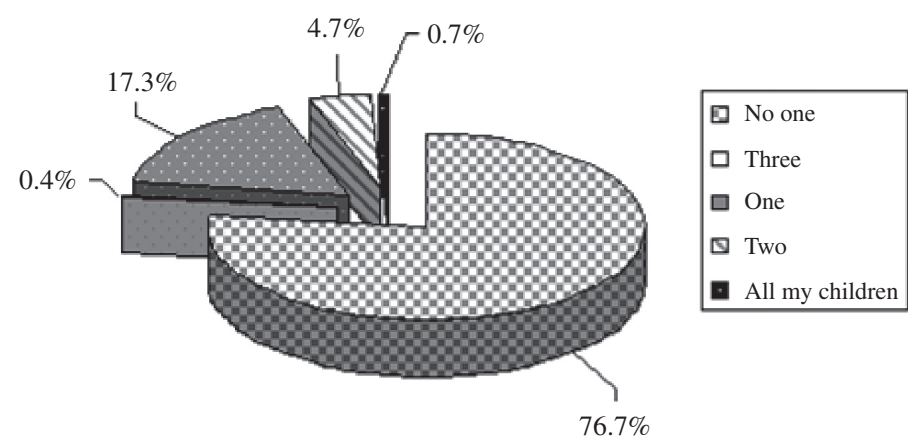

Figure 14: Farmers' answers about the number of children who are going to be involved in agriculture.

is negative and they believe that the new countries will not manage to cope with the new demands. A restriction of the agricultural sector is also revealed due to the fact that only older farmers are involved in it, while there is weak participation of the younger ones. The restricted participation in the European programs is explained by the fact that the producers are not sufficiently informed about them and that the information comes from informal sources. The low agricultural income forces a number of farmers to continue being occupied with multitasking, besides agricultural, activities, while an inability to protect the agricultural income after the pause of guaranteed prices is observed. A majority of the farmers would like an increase in the competition in the international market, continuous support from the EU, financial support of the agricultural income, flow of more money into structural programs, increase in the price of products, prohibition of imports from third countries and protection of the environment.

In conclusion, the present research showed that farmers' awareness about CAP, its reforms, the procedures provided, the benefits that can result from its reforms for the farmer's income, as well as the new environment which forms the primary sector present serious deficits and result in the need for implementing other, more sufficient, methods and ways for the dissemination of relevant information. 


\section{PROPOSALS}

Based on the results of the present research, the following proposals are suggested. Motivation for the creation of standardized processing units, with an emphasis on high quality products. Creation of cooperatives for the better distribution and trading of agricultural products in order to help the farmers obtain the highest benefits from the sale of their products. Motivation for young farmers to stay in their hometowns and avoid the depopulation of the countryside, by providing the most basic facilities, that is, education and training. Creation of specialized information centers near the villages, with the aim of organizing training and awareness programs for farmers at both the theoretical and the practical level on a variety of subjects such as the improvement of their crops, new techniques, new crops, issues about CAP and European Programs. Promotion of biological agriculture provided that its products stand high in consumers' preference and that the low production per hectare is compensated by the high prices they obtain. Moreover, they secure the protection of the environment as well as farmers' and consumers' good health as there is no or less use of chemicals. Research conducted by government services for the needs of the market at an international level and organization of the production in this direction. Linkage of universities and research institutions with agricultural processes for the promotion of innovative techniques and contemporary technology adapted to the needs of Greek agriculture. Financial support to farmers who wish, in cooperation with research institutions, to establish new and experimental crops or use new techniques as a motivation for their implementation. Improvement of trade networking of agricultural products, since due to the geographical location of the country and the high product diversity, the export to countries of North Europe, where there is a bigger demand at least for fresh fruits and vegetables, is hindered. Cooperation of Greek trade agencies with big chains of supermarkets in the countries where the products are exported, as Greek products very often lose their competitive advantage when they are transferred through intermediate stations, because of the increase in their price.

Nevertheless, it should be made clear that, despite both the EU and the Greek Government's measures through the prefectures and the Headquarters of Agricultural Development, the situation cannot be improved unless farmers realize that they must act in such a way so as to change radically the way of land exploitation through a new and very different European framework.

\section{REFERENCES}

[1] Vakakis, F., The future image of Greek agriculture (in Greek). Agriculture - Livestock Breeding. (7), 2007.

[2] http://ec.europa.eu/agriculture/agrista/2006

[3] http://www.livepedia.gr/index.php

[4] http://www.ornithologiki.gr/gr/kap/gr/agdreferences.htm

[5] http://www.minagric.gr

[6] http://www.el.wikipedia.org/wiki

[7] Baltas, C.N., Structural reform and transformation of organizations and business. The Effects of the Reform of the Common Agricultural Policy on EU Agriculture, eds J.A. Brox, R. Catterall \& P.E. Koveos, APF Press: Toronto, 2006.

[8] http://www.ornithologiki.gr/gr/hos/dt/dt_01_07_03.htm

[9] http://www.inkamak.gr/a_per.htm

[10] http://www.archive.gr/modules.php?name=News\&file=article\&sid=31

[11] http://www.georgia-gr.htm

[12] http://www.agrogi.gr/files/pdf/politemahismos.pdf

[13] http://www.paseges.gr/portal/cl/tn/Record/co/e66cee46-99fc-4711-aac7-d0b196cbc90b

[14] http://www.geo.gr/map.htm 
[15] Tzortzios, S., Biometry (in Greek), University of Thessaly, Volos, 2005.

[16] Kazakopoulos, L., Ageing of Agricultural Population and Attraction of Young Farmers (in Greek), report, 2005.

[17] http://www.ecocrete.gr

[18] Committee of European Union, The Agriculture's Situation in the Union, 1988 (in Greek).

[19] Maltby, L., The Common Agricultural Policy in Simple Words, Augene Leguen de Lacroix, 2005.

[20] Polymeros, K., Agricultural Development (in Greek), University of Thessaly, Volos, Greece, 2005.

[21] Konstadinidis, G., Farmers' training as a means for the improvement of competition and the reduction of employment. www.oreeka-dimitra.org.gr, 2004.

[22] http://ec.europa.eu/agriculture/envir/index_el.htm

[23] http://www.euro-info.gr/showProductsbyld.asp?Product_id=31575

[24] Greek Ministry of Agriculture and Gaia Center-Goulandris Natural History Museum, Proceedings of the Congress "Agriculture and Environment" (in Greek), 25 February 2000, Athens, 2000.

[25] Kasoulidis, I., The Future of Agricultural Economy in the New European Environment (in Greek), report, 2006.

[26] Kounias, S., Koliva-Machaira, F., Bagiatis, K. \& Bora-Senta, E., Introduction to Statistics (in Greek), Xristodoulidis Editions: Thessaloniki, 2006. 